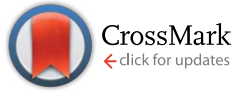

Cite this: RSC Adv., 2017, 7, 7401

\title{
Palladium-catalyzed three-component tandem cyclization of buta-2,3-dien-1-ol, aryl iodides, and imines: an efficient protocol for the synthesis of oxazolidine derivatives $\uparrow$
}

\author{
Yunlei Hou, \$ Mingze Qin, \Xiuxiu Yang, Qi Shen, Yanfang Zhao, Yajing Liu* \\ and Ping Gong*
}

Received 6th November 2016 Accepted 7th December 2016

An efficient three-component tandem cyclization reaction for the synthesis of highly substituted oxazolidines was achieved through the $\mathrm{Pd}^{0}$-catalyzed cyclization of buta-2,3-dien-1-ol with aryl iodides and imines. A range of $\mathrm{R}^{1}$ and $\mathrm{R}^{2}$ functional groups is well-tolerated while affording cyclization products in moderate yields and with moderate to high diastereoselectivities.

For instance, the anticancer drug doxorubicin (Fig. 1, v) could be transformed into the oxazolidine prodrug VI to increase tumor response and minimize side effects, especially the treatment-limiting cardiotoxicity associated with doxorubicin therapy. ${ }^{6}$ Accordingly, the development of new methodologies for the synthesis of oxazolidines has garnered considerable attention.

Recently, Yoon et al. developed an efficient method for synthesizing oxazolidines through the iron- or copper-catalyzed aminohydroxylation of olefins (Scheme 1, Eq (1)). ${ }^{7}$ Jarvo further demonstrated the stereoselective and stereospecific syntheses of oxazolidines using catalysts with differing rates of allylmetal isomerization (Scheme 1, Eq (2)). ${ }^{8}$ Zhang investigated the [3+2] cycloaddition of azomethine ylides with carbonyl compounds for the synthesis of oxazolidines (Scheme 1, Eq (3)). ${ }^{9}$ More

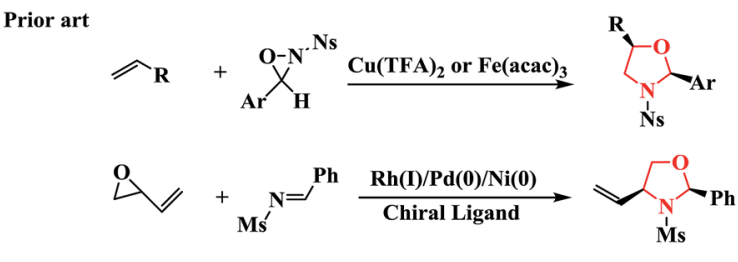

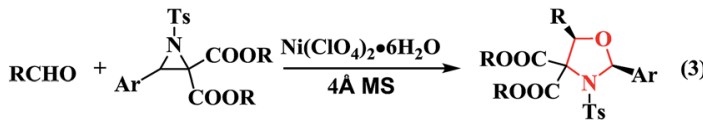

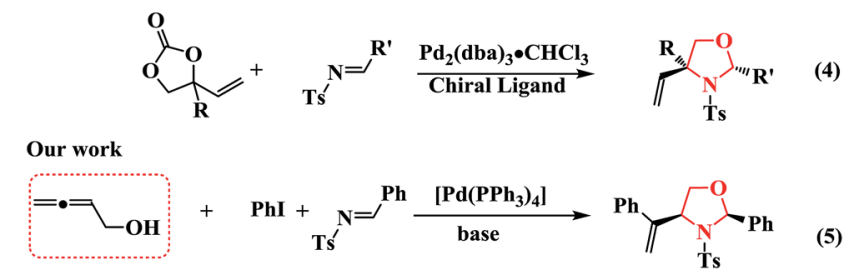

Key Laboratory of Structure-based Drug Design and Discovery (Shenyang Pharmaceutical University), Ministry of Education, 103 Wenhua Road, Shenhe District, Shenyang 110016, People's Republic of China. E-mail: gongpinggp@126. com; lyjpharm@126.com

$\dagger$ Electronic supplementary information (ESI) available. CCDC 1516742. For ESI and crystallographic data in CIF or other electronic format see DOI: 10.1039/c6ra27993g

\$ These authors contributed equally to this work.
Scheme 1 Strategies for the construction of oxazolidines. 
recently, Zhang explored a new organocatalytic strategy to synthesize oxazolidines through the Pd-catalyzed asymmetric decarboxylative cycloaddition of vinylethylene carbonates (VECs) with imines in the presence of chiral ligands (Scheme 1, Eq (4)). ${ }^{10}$ Therefore, the development of operationally simple and efficient synthetic approaches towards oxazolidines using readily available and stable starting materials is desired.

Multi-component reactions (MCRs) involving domino processes have emerged as powerful tools for the synthesis of molecules, including heterocyclic compounds, with efficiency, atom-economy, and diversity from simple substrates. ${ }^{\mathbf{1 1}}$ In addition, functionalized allenes have been shown to be efficient starting materials for the synthesis of potentially useful carboand heterocycles. ${ }^{12}$ Inspired by the synthesis of 1,3-oxazolidines from the cycloaddition of imines and vinyl epoxides (Scheme 1, Eq (2)) or VECs (Scheme 1, Eq (4)), we hypothesized that other substrates, such as terminal $\beta$-allenols instead of vinyl epoxides or VECs, could be involved in the $\mathrm{Pd}^{0}$-catalyzed reaction of organic halides and imines without the necessity of a chiral ligand, which would allow for the formation of oxazolidine derivatives (Scheme 1, Eq (5)). Towards that end, we developed a novel and efficient route towards 1,3-oxazolidines via the cycloaddition of buta-2,3-dien-1-ol (1a) with aryl iodides and imines by varying the reaction conditions.

\section{Results and discussion}

Based on literature precedent, ${ }^{\mathbf{1 3 , 1 4}}$ we set out to test the model reaction of buta-2,3-dien-1-ol (1a) with iodobenzene (2a) and imine (3a) in the presence of $5 \mathrm{~mol} \%$ of $\left[\mathrm{Pd}\left(\mathrm{PPh}_{3}\right)_{4}\right]$ at $80{ }^{\circ} \mathrm{C}$, as shown in Table 1 . The reaction in THF with $\mathrm{K}_{2} \mathrm{CO}_{3}$ as the base afforded oxazolidine $4 a$ in $23 \%$ yield with a dr of $3: 1$ (Table 1 , entry 1). In order to improve the yield and stereoselectivity, different bases, solvents, and additives were tested. Among the tested bases, CsF and $\mathrm{Cs}_{2} \mathrm{CO}_{3}$ resulted in higher efficiencies with $50 \%$ and $38 \%$ yields, respectively (Table 1, entries 4-5), while $\mathrm{Na}_{2} \mathrm{CO}_{3}$ only gave the product in a trace yield (Table 1 , entry 3). Polar solvents such as DMSO and DMF resulted in moderate stereoselectivity with a $>25: 1 \mathrm{dr}$ (Table 1 , entries 9 and 11). Less polar solvents such as toluene decreased the diastereoselectivity to $8: 1$ and resulted in an 18\% yield (Table 1 , entry 7 ). When the reaction was conducted in dioxane, 4aa was obtained in 50\% yield with a $>30: 1 \mathrm{dr}$ (Table 1 , entry 10). Next, the reaction temperature was examined. Upon lowering the temperature to $40{ }^{\circ} \mathrm{C}$, the conversion dramatically dropped to only $10 \%$, even when the reaction time was extended to $48 \mathrm{~h}$. Higher temperatures $\left(100{ }^{\circ} \mathrm{C}\right)$ accelerated the reaction rate without any increase in the yield (Table 1, entries 10 and 15). On the basis of previous studies, various additives were tested (Table 1, entries 12-13). Among them, the phase-transfer catalyst $n-\mathrm{Bu}_{4} \mathrm{NBr}$ had no dramatic effect on the stereoselectivity. The Lewis acid $\mathrm{Cu}(\mathrm{OTf})_{2}$ did not improve the yields, but the cis/ trans ratio decreased to $10: 1$. An increase in the molar amount of imine 3a from 1.2 to 3.0 equiv. also gave a similar result (Table 1, entries 1 vs. 2, 15 vs. 16). Higher palladium concentrations (from $5 \mathrm{~mol} \%$ to $50 \mathrm{~mol} \%$ ) was tried in order to improve the yield, but the yield did not increased (Table 1 , entry 17). Overall, the best results were obtained when 3.0 equiv. of

Table 1 The effect of different reaction conditions on the $\mathrm{Pd}^{0}$-catalyzed three-component tandem cyclization reaction of $1 \mathrm{a}, 2 \mathrm{a}$, and $3 \mathrm{a}^{a}$

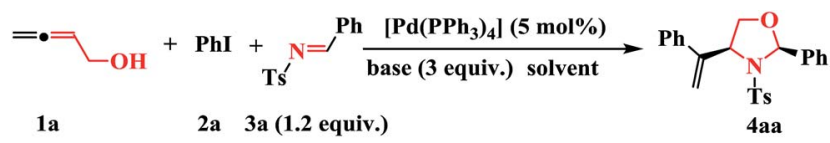

\begin{tabular}{|c|c|c|c|c|c|c|c|}
\hline Entry & Base & Additive & Solvent & Temp $\left({ }^{\circ} \mathrm{C}\right)$ & Time (h) & Yield $^{b}(\%)$ & $\mathrm{dr}^{c}$ (cis/trans $)$ \\
\hline 1 & $\mathrm{~K}_{2} \mathrm{CO}_{3}$ & - & THF & Reflux & 15 & 23 & $3: 1$ \\
\hline $2^{e}$ & $\mathrm{~K}_{2} \mathrm{CO}_{3}$ & - & THF & Reflux & 15 & 25 & $3: 1$ \\
\hline 4 & $\mathrm{Cs}_{2} \mathrm{CO}_{3}$ & - & THF & Reflux & 12 & 38 & $10: 1$ \\
\hline 5 & CsF & - & THF & Reflux & 10 & 50 & $15: 1$ \\
\hline 6 & CsF & - & $\mathrm{CH}_{3} \mathrm{CN}$ & Reflux & 10 & 48 & $20: 1$ \\
\hline 9 & $\mathrm{CsF}$ & - & DMSO & 80 & 12 & 43 & $25: 1$ \\
\hline 10 & CsF & - & Dioxane & 80 & 10 & 50 & $>30: 1$ \\
\hline 11 & $\mathrm{CsF}$ & - & DMF & 80 & 10 & 45 & $25: 1$ \\
\hline 12 & $\mathrm{CsF}$ & $\mathrm{A}^{d}$ & Dioxane & 80 & 10 & 48 & $>30: 1$ \\
\hline 13 & CsF & $\mathrm{B}^{d}$ & Dioxane & 80 & 10 & 50 & $10: 1$ \\
\hline 14 & $\mathrm{CsF}$ & - & Dioxane & 40 & 48 & 10 & - \\
\hline
\end{tabular}

${ }^{a}$ Reaction conditions: under a $\mathrm{N}_{2}$ atmosphere, 1a $\left(0.35 \mathrm{mmol}, 1\right.$ equiv.), 2a $(0.42 \mathrm{mmol}, 1.2$ equiv. $), 3 \mathrm{a}\left(0.42 \mathrm{mmol}, 1.2\right.$ equiv.), $\left[\mathrm{Pd}\left(\mathrm{PPh}_{3}\right)_{4}\right]$ (0.018 mmol, $5 \mathrm{~mol} \%)$, base $\left(1 \mathrm{mmol}, 3\right.$ equiv.), solvent $(3.0 \mathrm{~mL}) .{ }^{b}$ Isolated yield. ${ }^{c}$ Determined by ${ }^{1} \mathrm{H} \mathrm{NMR}^{d}{ }^{d} \mathrm{~A}=n$-Bu $4 \mathrm{NBr}(5 \mathrm{~mol} \%), \mathrm{B}=$ $\mathrm{Cu}(\mathrm{OTf})_{2}(5 \mathrm{~mol} \%) .{ }^{e}$ Imine $3 \mathrm{a}\left(3.0\right.$ equiv.) was used. ${ }^{f}\left[\mathrm{Pd}\left(\mathrm{PPh}_{3}\right)_{4}\right](20 \mathrm{~mol} \%$ or $50 \mathrm{~mol} \%)$ was used. 
CsF was used as the base in the presence of $5 \mathrm{~mol} \%\left[\mathrm{Pd}\left(\mathrm{PPh}_{3}\right)_{4}\right]$ in dioxane at $80^{\circ} \mathrm{C}$.

Under the optimized reaction conditions, the scope and limitations of the transformation were evaluated for the reaction of $1 \mathrm{a}$ with various imines 3 ; the results are listed in Table 2. Tandem reactions with imines derived from arylaldehydes with different steric and electronic features proceeded smoothly to afford the corresponding oxazolidines 4 in moderate yields and diastereoselectivities (Table 2, entries 1-14). The position of the substituents on the aryl ring affected the reactivity. For example, $p$-fluorophenyl-substituted $\mathbf{3 f}$ afforded the desired cycloaddition product 4 af in $48 \%$ yield with a dr of $10: 1$ under the optimized conditions (Table 2, entry 6). In contrast, ofluorophenyl-substituted $\mathbf{3 g}$ exhibited a decreased conversion with low diastereoselectivity, indicating that $o$-substitution on the aryl ring is unfavorable (Table 2, entry 7 ). The reaction efficiency and diastereomeric ratio decreased dramatically when multiple-halogen atoms were present on the aryl ring, implying that stereospecific blockade groups have a negative effect on the cycloaddition reaction (Table 2, entries 10 and 11). Imines $\mathbf{3} \mathbf{l}$ and $\mathbf{3 m}$, derived from 2-formylthiofuran and furfural, were also suitable substrates for the cycloaddition and furnished the corresponding oxazolidines in $47 \%$ and $43 \%$ yields, respectively (Table 2, entries 12-13). However, imine 30 $\left(\mathrm{R}^{1}=2\right.$-pyrrolyl $)$ gave the product 4 ao in only a trace yield,

Table 2 The $\mathrm{Pd}^{0}$-catalyzed three-component tandem cyclization reaction of $1 \mathrm{a}$, iodobenzene $2 \mathrm{a}$, and different imines ${ }^{a}$

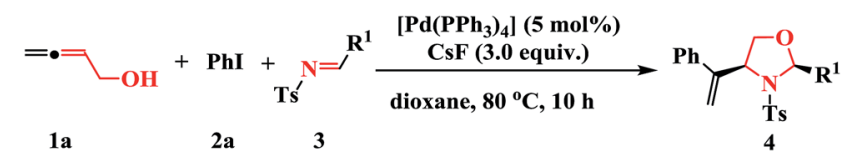

\begin{tabular}{|c|c|c|c|c|}
\hline Entry & 3 & 4 & Yield $^{b}(\%)$ & $\mathrm{dr}^{c}($ cis/trans \\
\hline 1 & $3 \mathbf{a}\left(\mathrm{R}^{1}=\mathrm{Ph}\right)$ & $4 \mathbf{a a}$ & 50 & $>30: 1$ \\
\hline 2 & $3 \mathbf{b}\left(\mathrm{R}^{1}=p-\mathrm{MeC}_{6} \mathrm{H}_{4}\right)$ & $4 a b$ & 55 & $15: 1$ \\
\hline 3 & $3 \mathrm{c}\left(\mathrm{R}^{1}=p-\mathrm{MeOC}_{6} \mathrm{H}_{4}\right)$ & $4 a c$ & 52 & $>30: 1$ \\
\hline 4 & 3d $\left(\mathrm{R}^{1}=m-\mathrm{MeC}_{6} \mathrm{H}_{4}\right)$ & 4ad & 45 & $10: 1$ \\
\hline 5 & $3 \mathbf{e}\left(\mathrm{R}^{1}=p-\mathrm{ClC}_{6} \mathrm{H}_{4}\right)$ & $4 a e$ & 51 & $8: 1$ \\
\hline 6 & $3 \mathbf{f}\left(\mathrm{R}^{1}=p-\mathrm{FC}_{6} \mathrm{H}_{4}\right)$ & 4af & 48 & $10: 1$ \\
\hline 7 & $3 \mathrm{~g}\left(\mathrm{R}^{1}=o-\mathrm{FC}_{6} \mathrm{H}_{4}\right)$ & $4 a g$ & 30 & $3: 1$ \\
\hline 8 & $3 \mathbf{h}\left(\mathrm{R}^{1}=o-\mathrm{ClC}_{6} \mathrm{H}_{4}\right)$ & $4 \mathrm{ah}$ & 28 & $5: 1$ \\
\hline 9 & $3 \mathbf{i}\left(\mathrm{R}^{1}=p-\mathrm{BrC}_{6} \mathrm{H}_{4}\right)$ & $4 a i$ & 54 & $4: 1$ \\
\hline 10 & $3 \mathbf{j}\left(\mathrm{R}^{1}=2,4-(\mathrm{F})_{2}-\mathrm{C}_{6} \mathrm{H}_{4}\right)$ & 4aj & 25 & $3: 1$ \\
\hline 11 & $3 \mathbf{k}\left(\mathrm{R}^{1}=2-\mathrm{Cl}, 4-\mathrm{F}-\mathrm{C}_{6} \mathrm{H}_{4}\right)$ & 4ak & 18 & $2: 1$ \\
\hline 12 & $3 \mathbf{l}\left(\mathrm{R}^{1}=2\right.$-thienyl $)$ & 4al & 47 & $4: 1$ \\
\hline 13 & $3 \mathbf{m}\left(\mathrm{R}^{1}=2\right.$-furyl $)$ & $4 a m$ & 43 & $2: 1$ \\
\hline 14 & $3 \mathbf{n}\left(\mathrm{R}^{1}=\mathrm{Ph}\right)^{d}$ & $4 a n$ & 45 & $4: 1$ \\
\hline 15 & $30\left(\mathrm{R}^{1}=2\right.$-pyrrolyl $)$ & 4 ao & Trace & - \\
\hline 16 & $3 \mathbf{p}\left(\mathrm{R}^{1}=\mathrm{Ph}\right)^{e}$ & 4ap & Trace & - \\
\hline
\end{tabular}

${ }^{a}$ Reaction conditions: under a $\mathrm{N}_{2}$ atmosphere, $\mathbf{1 a}(0.35$ mmol, 1 equiv.), 2a (0.42 mmol, 1.2 equiv.), 3a (0.42 mmol, 1.2 equiv.), $\left[\mathrm{Pd}\left(\mathrm{PPh}_{3}\right)_{4}\right]$ (0.018 mmol, $5 \mathrm{~mol} \%)$, CsF (1 mmol, 3 equiv.), dioxane $(3.0 \mathrm{~mL})$. ${ }^{b}$ Isolated yield. ${ }^{c}$ Determined by ${ }^{1} \mathrm{H}$ NMR. The absolute configuration of 4aa was determined by X-ray crystallography (see Fig. 2); those of the other products were assigned by analogy. ${ }^{d} \mathbf{3 n}=(E)-N-$ benzylidenemethanesulfonamide. ${ }^{e} 3 \mathbf{p}=(E)$-N,1-diphenylmethanimine or (E)-N-(4-methoxyphenyl)-1-phenylmethanimine. indicating that it was significantly less reactive than $3 \mathbf{l}\left(\mathrm{R}^{1}=2\right.$ thienyl) and $\mathbf{3 m}\left(\mathrm{R}^{1}=2\right.$-furyl). Gratifyingly, $(E)$ - $N$-mesyl imine 3n was a viable substrate in this transformation, affording the product in $45 \%$ isolated yield under the standard conditions. When using imines $\mathbf{3 p}$ with phenyl or $p$-methoxyl phenyl groups at nitrogen, the target product was not detected, which suggesting that imines with electron-withdrawing groups at nitrogen was necessary in this reaction. The structures and relative stereochemistries of the products were established by Xray crystallography analysis of 4 aa as the 2,4-cis-isomer (Fig. 2), and those of the other products were assigned by analogy.

After the successful cycloaddition of 1a and iodobenzene 2a with various imines, we subsequently turned our attention toward the cycloaddition of $\mathbf{1 a}$ and $(E)$ - $N$-benzylidenetosylamide 3a with various aryl iodides; the results are summarized in Table 3. In general, aryl iodides bearing electron-withdrawing (Table 3, entries 4-5) or electron-donating groups (Table 3, entries 2-3) afforded the corresponding oxazolidines in moderate yields and diastereoselectivities under identical conditions. Furthermore, the incorporation of multiplehalogens or strong EWGs on the phenyl ring decreased the
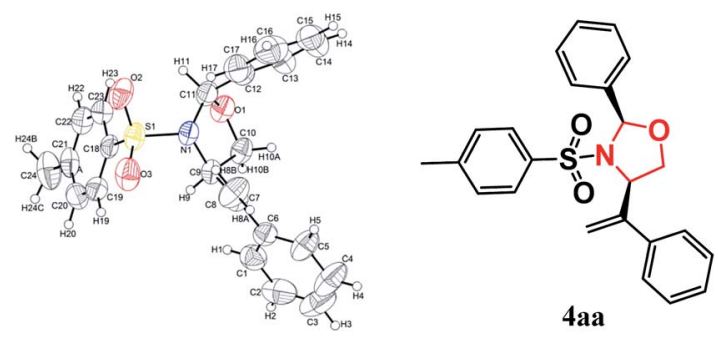

Fig. 2 X-ray crystal structure of compound 4 aa.

Table 3 The $\mathrm{Pd}^{0}$-catalyzed three-component tandem cyclization reaction of $1 a$, imine $3 a$, and different aryl iodides ${ }^{a}$

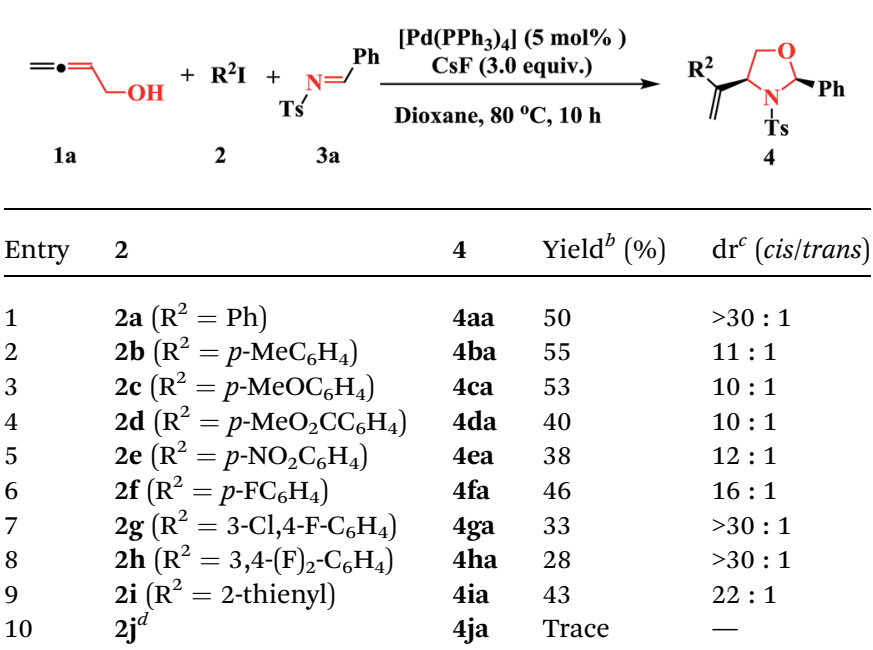

${ }^{a}$ Reaction conditions: under a $\mathrm{N}_{2}$ atmosphere, $1 \mathrm{a}(0.35 \mathrm{mmol}, 1$ equiv. $)$, 2a $\left(0.42 \mathrm{mmol}, 1.2\right.$ equiv.), 3a $(0.42 \mathrm{mmol}, 1.2$ equiv. $),\left[\mathrm{Pd}\left(\mathrm{PPh}_{3}\right)_{4}\right]$ (0.018 mmol, $5 \mathrm{~mol} \%)$, CsF ( $1 \mathrm{mmol}, 3$ equiv.), dioxane $(3.0 \mathrm{~mL})$. ${ }^{b}$ Isolated yield. ${ }^{c}$ Determined by ${ }^{1} \mathrm{H}$ NMR. ${ }^{d} \mathbf{2 j}=$ phenyl bromide or phenyl chloride. 


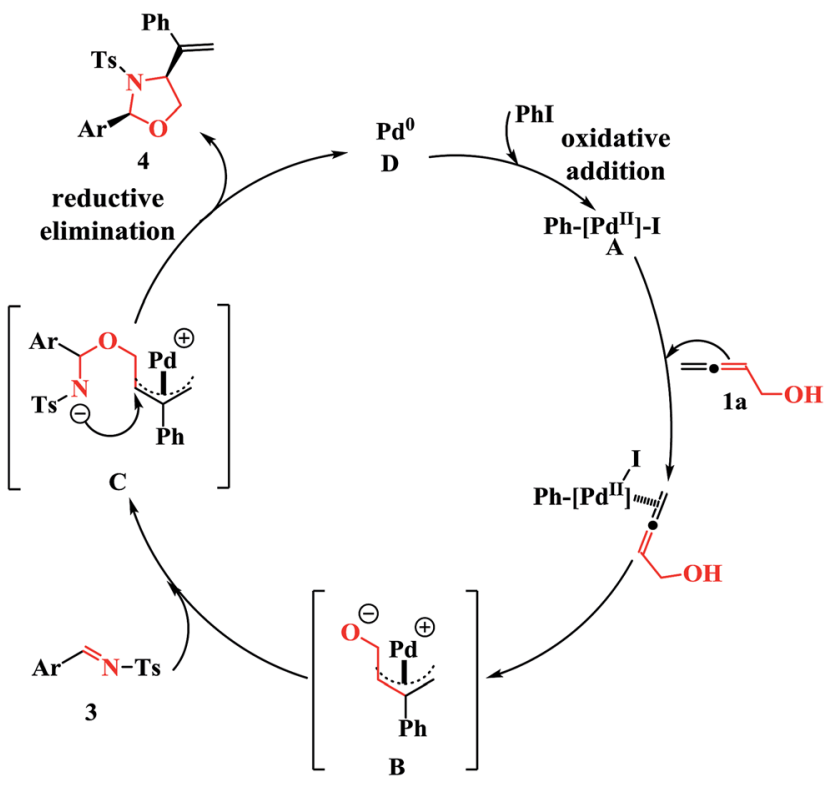

Scheme 2 Plausible reaction mechanism.

reaction efficiency, which suggested that the electron density of the phenyl ring played a role in the reaction efficiency (Table 3, entries 4-5, 7-8, 28-40\%). Notably, when a heteroaryl iodide was employed as a substrate (Table 3 , entry $9,43 \%$ ), the product yield was slightly affected, which was attributed to the electronic property of the thiophene ring. In order to investigate the limitations of aryl halides with different carbon-halogen bonds, phenyl bromide and phenyl chloride were tested. As presented in Table 3 (entries 10 vs. 1), only the carbon-iodine bond was cleaved, suggesting that aryl iodides resulted in higher efficiencies. Interestingly, compounds 4aa-4ia ( $d r>10: 1)$ in Table 3 gave a higher diastereomeric ratio than compounds 4ad-4an $(\mathrm{dr}=2: 1-10: 1)$ in Table 2 , which indicated that $\mathrm{R}^{2}$ has a more general substrate scope.

Based on previous studies, ${ }^{15}$ a plausible mechanism for the cross-coupling reaction is proposed in Scheme 2. The carbopalladation of PhPdI, which is formed in situ from the oxidative addition of $\mathrm{Pd}^{0}$ to iodobenzene, with buta-2,3-dien-1-ol (1a) at the center carbon atom forms the $\pi$-allylic palladium complex B. Subsequent nucleophilic attack of the oxygen nucleophile of B on the imines $\mathbf{3}$ leads to the intermediate C. Finally, the resulting intermediate $\mathbf{C}$ undergoes an intramolecular nucleophilic attack on the inner $\pi$-allylic carbon atom to produce the cyclized products 4 , along with the regeneration of the $\mathrm{Pd}^{0}$ catalyst $\mathbf{D}$.

\section{Conclusions}

In conclusion, we have developed an efficient $\mathrm{Pd}^{0}$-catalyzed MCR for the synthesis of polysubstituted oxazolidine derivatives from buta-2,3-dien-1-ol, aryl iodides, and imines. Because of the three-component reaction concept, this cyclization could provide multiple points for diversity with excellent diastereoselectivity. As all three building blocks are readily available, this study will advance the transition-metal-catalyzed chemistry of allenes. Further studies regarding the scope and synthetic applications of this reaction are being pursued in our laboratory and will be reported in due course.

\section{Acknowledgements}

We are grateful for the financial support from the Program for Innovative Research Team of the Ministry of Education and Program for Liaoning Innovative Research Team in University (IRT1073).

\section{References}

1 A. Barghi-Lish, S. Farzaneh and M. Mamaghani, Synth. Commun., 2016, 46, 1209.

2 (a) J. D. Scott and R. M. Williams, Chem. Rev., 2002, 102, 1669; (b) R. M. Williams, T. Glinka, M. E. Flanagan, R. Gallegos, H. Coffman and D. Pei, J. Am. Chem. Soc., 1992, 114, 733; (c) F. Tomita, K. Takahashi and T. Tamaoki, Antibiotics, 1984, 37, 1268; (d) Y.-C. Wu, M. Liron and J. Zhu, J. Am. Chem. Soc., 2008, 130, 7148; (e) M. Yotsu-Yamashita, Y. H. Kim, S. C. Dudley Jr, G. Choudhary, A. Pfahnl, Y. Oshima and J. W. Daly, Proc. Natl. Acad. Sci. U. S. A., 2004, 101, 4346.

3 (a) A. Pastor, W. Adam, T. Wirth and G. Tóth, Eur. J. Org. Chem., 2005, 14, 3075; (b) I. Hoppe, H. Hoffmann, I. Grtner, T. Krettek and D. Hoppe, Synthesis, 1991, 12, 1157; (c) C. Scolastico, Pure Appl. Chem., 1988, 60, 1689; (d) D. A. Evans, M. D. Ennis and D. J. Mathre, J. Am. Chem. Soc., 1982, 104, 1737; (e) S. Kanemasa and K. Onimura, Tetrahedron, 1992, 48, 8631; $(f)$ N. Hiroto, O. Yuko and K. Eunsang, Heterocycles, 2014, 89, 1.

4 (a) C. Wolf and H. Xu, Chem. Commun., 2011, 47, 3339; (b) C. Agami and F. Couty, Eur. J. Org. Chem., 2004, 4, 677; (c) A. Tessier, N. Lahmar, J. Pytkowicz and T. Brigaud, J. Org. Chem., 2008, 73, 3970; (d) C. A. Caputoand and N. D. Jones, Dalton Trans., 2007, 41, 4627-4640.

5 (a) G. P. Moloney, D. J. Craik, M. N. Iskander and T. L. Nero, J. Chem. Soc., Perkin Trans. 2, 1998, 2, 199; (b) J. Danielsson, L. Toomand and P. Somfai, Eur. J. Org. Chem., 2011, 3, 607; (c) B. Seashore-Ludlowand and P. Somfai, Eur. J. Org. Chem., 2010, 20, 3927; (d) T. H. Fife and L. Hagopian, J. Am. Chem. Soc., 1968, 90, 10074; (e) F. Gosselin, A. Roy, P. D. O'Shea, C. Chen and R. P. Volante, Org. Lett., 2004, 6, 641.

6 (a) G. C. Post, B. L. Barthel, D. J. Burkhart, J. R. Hagadorn and T. H. Koch, J. Med. Chem., 2005, 48, 7648; (b) D. J. Burkhart, B. L. Barthel, G. C. Post, B. T. Kalet, J. W. Nafie, R. K. Shoemaker and T. H. Koch, J. Med. Chem., 2006, 49, 7002; (c) G. Minotti, P. Menna, E. Salvatorelli, G. Cairo and L. Gianni, Pharmacol. Rev., 2004, 56, 185; (d) D. A. Gewirtz, Biochem. Pharmacol., 1999, 57, 727.

7 (a) D. J. Michaelis, C. J. Shaffer and T. P. Yoon, J. Am. Chem. Soc., 2007, 129, 1866-1867; (b) D. J. Michaelis, M. A. Ischay and T. P. Yoon, J. Am. Chem. Soc., 2008, 130, 6610-6615; (c) 
K. S. Williamson and T. P. Yoon, J. Am. Chem. Soc., 2010, 132, 4570-4571.

8 M. B. Shaghafi, R. E. Grote and E. R. Jarvo, Org. Lett., 2011, 13, 5188.

9 X. Wu, L. Li and J. Zhang, Chem. Commun., 2011, 47, 7824. 10 L. Yang, A. Khan, R. Zheng, L. Y. Jin and Y. J. Zhang, Org. Lett., 2015, 17, 6230.

11 (a) X. Chu, X. Xu and S. Ji, Chem.-Eur. J., 2016, 22, 14181; (b) M. Ghorbani, B. Mohammadi, M. Saraii, B. Masoumi, M. Abbasian, A. Ramazani, K. Slepokura and T. Lis, Org. Lett., 2016, 18, 4759; (c) L. G. Voskressensky, T. N. Borisova, M. D. Matveeva, V. N. Khrustalev, A. V. Aksenov, A. A. Titov, A. E. Vartanova and A. V. Varlamova, $R S C$ Adv., 2016, 6, 74068; (d) H. Dong, L. Xu, S. Li, L. Wang, C. Shao and J. Xiao, ACS Comb. Sci., 2016, 18, 604; (e) X. Lian, J. Meng and Z. Han, Org. Lett., 2016, 18, 4270; (f) J. Chu, B. Hu, Z. Liao and X. Zhang, J. Org. Chem., 2016, 81, 8647.

12 (a) B. Miao, S. Li, G. Li and S. Ma, Org. Lett., 2016, 18, 2556; (b) T. Cao and S. Ma, Org. Lett., 2016, 18, 1510; (c) W. Yuan and S. Ma, Org. Lett., 2014, 16, 193; (d) J. Ye and S. Ma, Acc. Chem. Res., 2014, 47, 989; (e) X. Huang, W. Wu, S. Song, C. Fu and S. Ma, Adv. Synth. Catal., 2016, 358, 2791; (f) Y. Shigeo, K. Yasuaki, O. Yuta and M. Chisato, Chem.-Eur. J., 2016, 22, 12181; (g) T. Aurelien, B. Aurelie, N. W. Vijay and L. Benjamin, Angew. Chem., Int. Ed., 2016, 55, 8962; (h) G. Charlotte, M. Veronique and T. Y. Patrick, Org. Lett., 2016, 18, 676.

13 S. Ma and N. Jiao, Angew. Chem., Int. Ed., 2002, 41, 4737. 14 X. Cheng and S. Ma, Angew. Chem., Int. Ed., 2008, 47, 4581. 15 (a) A. Khan, J. Xing, J. Zhao, Y. Kan, W. Zhang and Y. Zhang, Chem.-Eur. J., 2015, 21, 120; (b) J. Cheng, X. Jiang, C. Zhu and S. Ma, Org. Lett., 2011, 353, 1676; (c) J. Ye and S. Ma, Acc. Chem. Res., 2014, 47, 989; (d) Q. Xiao, B. Wang, L. Tian, Y. Yang, J. Ma, Y. Zhang, S. Chen and J. Wang, Angew. Chem., Int. Ed., 2013, 52, 9305; (e) P. Miao, H. Wang, L. Liu, W. Chang and J. Li, Asian J. Org. Chem., 2015, 4, 1050; (f) J. Le Bras and J. Muzart, Chem. Soc. Rev., 2014, 43, 3003; $(g)$ R. W. Bates and V. atcharoen, Chem. Soc. Rev., 2002, 31, 12 . 